\title{
PERTANGGUNGJAWABAN DOKTER DAN MODEL PENYELESAIAN PERKARA MALPRAKTIK MEDIK DI INDONESIA
}

\author{
Tri Handayani \\ Bagian Hukum Pemkab. Blitar \\ Email: mizanjurnalilmuhukum@gmail.com
}

\begin{abstract}
There is an international tendency to divert medical dispute from the litigation model (in court settlement) to the out-of-court dispute models (out of court settlement) which leads to the win-win situation of the paradigm.

This paradigm has actually started to be adopted in Indonesia only the implementation is still not encouraging. Law Number 36 Year 2009 on Health (Health Law) provides that disputes arising out of negligence of health personnel must be resolved through mediation (Article 29). This provision has not fully become the reference of the public and law enforcement officers related to the settlement of medical disputes in Indonesia. The tendency of patients in Indonesia to prosecute doctors through legal channels is still quite high. This is further exacerbated by the attitude of law enforcement officers who seem less concerned with the provisions of Article 29 of Law Number 36 Year 2009 on Health above.

The application of mediation means in the dispute of medical disputes as required by article 29 of the Health Law faces a number of obstacles in the field. One of the obstacles is the lack of implementing regulations that explain how such mediation mechanisms should technically be run. There are a number of laws and regulations governing mediation such as Supreme Court Regulation No. 1 of 2008 on Mediation Procedures in Courts and Law No. 30 of 1999 on Arbitration and Alternative Dispute Settlement. Supreme Court Regulation No. 1 of 2008 regulates the court-annexed mediation while Law Number 30 Year 1999 regulates the arbitration and Alternative Dispute Resolution (ADR) institutions. In addition, there are also some institutions that perform mediation functions such as: Consumer Dispute Settlement Agency (BPSK), Ombudsman, and Badan Pengawas Rumah (RSB). All such institutions are deemed relevant for the settlement of medical disputes. It is thus quite confusing at the operational level.

Keywords: Criminal Claims, Medical Malpractice, Dispute Settlement, and Mediation.
\end{abstract}

\section{A. PENDAHULUAN}

Dalam pandangan dokter, majelis hakim kasasi telah benar-benar menciptakan ketidakadilan pidana (criminal injustice) melalui putusannya dan karenanya aksi protes dalam bentuk mogok nasional mestinya dapat dimaklumi. Akan tetapi dari sudut pandang yang berbeda aksi mogok kalangan dokter tersebut tidak dapat diterima sehingga kontroversi terkait aksi ini pun terjadi di kalangan masyarakat. ${ }^{1}$ Tuntutan para dokter menolak kriminalisasi sebagaimana diteriakkan dalam setiap aksi protesnya mendapat kritik dari sebagian anggota masyarakat. Mereka menuduh dokter ingin

1 Anonim, “Aksi Mogok Dokter Bertentangan dengan Kemanusiaan", diunduh dari

http://www.tribunnews.com/nasional/2013/11/ 26/aksi-mogok-dokter-bertentangan-dengankemanusiaan, pada 13 Desember 2016, pukul 13.20 WIB. mendapatkan keistimewaan perlakuan di muka hukum yakni pengecualian dari pertanggungjawaban pidana.

Tujuan Penelitian

Penelitian ini diarahkan untuk mencapai tujuan-tujuan sebagai berikut:

1. Untuk mengetahui dan mengkaji bentukbentuk mekanisme penyelesaian sengketa yang dapat diterapkan pada perkara malpraktik medik di Indonesia;

2. Untuk menemukan model penyelesaian perkara malpraktik medik yang paling ideal sesuai dengan nilai-nilai budaya Indonesia.

\section{B. METODE PENELITIAN Jenis Penelitian}

Penelitian yang dilakukan merupakan gabungan antara penelitian hukum normatif dan empiris. Selain mengkaji bahan-bahan hukum yang berupa peraturan perundangundangan, buku-buku, artikel atau bahanbahan hukum lainnya yang relevan, peneliti juga melakukan studi lapangan melalui 
kegiatan wawancara dengan berbagai responden dan atau narasumber terkait.

\section{Data Penelitian}

Sesuai dengan jenis penelitiannya, data yang dikumpulkan adalah data primer maupun data sekunder. Data sekunder dalam penelitian ini berupa bahan-bahan hukum yang dapat kelompokkan menjadi tiga jenis yaitu:

a. Bahan hukum primer yaitu bahan-bahan hukum yang mengikat, berupa peraturan perundangundangan seperti KUHP, KUHPerdata, Undang-undang Nomor 29 Tahun 2004 Tentang Praktik Kedokteran, Undang-undang Nomor 36 tahun 2009 Tentang Kesehatan, Undang-undang Nomor 36 Tahun 2014 serta peraturan lain yang terkait.

b. Bahan hukum sekunder yaitu bahan hukum yang bersifat memberikan penjelasan atas bahan-bahan hukum primer yang terdiri dari buku-buku, paper, artikel, dan lain-lain.

c. Bahan hukum tersier yaitu bahan hukum yang bersifat memberikan petunjuk atau penjelasan mengenai bahan hukum primer maupun bahan hukum sekunder seperti kamus bahasa, kamus hukum dan sebagainya.

\section{Pengumpulan Data}

Data yang berupa bahan-bahan hukum dikumpulkan dengan cara melakukan studi kepustakaan. Studi kepustakaan dilakukan dengan cara membaca dan mengkaji secara cermat bahan-bahan hukum tersebut, baik yang berupa peraturan perundang-undangan yang terkait serta bukubuku, paper, atau artikel yang relevan guna memperoleh pemahaman yang mendalam sehingga dapat diolah dan dianalisis dengan baik. Sedangkan studi lapangan dilakukan melalui kegiatan wawancara dengan berbagai responden serta narasumber yang terkait. Responden dan atau narasumber penelitian yang pilih untuk dapat memberikan informasi yang relevan antara lain MKDKI, IDI, BANI, dan beberapa institusi rumah sakit baik yang dimiliki oleh pemerintah maupun swasta.

\section{Analisis Data}

Data sekunder yang telah diperoleh baik melalui studi pustaka disusun secara sistematis sehingga diperoleh gambaran yang menyeluruh mengenai model-model penyelesaian perkara malpraktik medik. Sedangkan data primer yang diperoleh melalui wawancara dengan nara sumber yang kompeten digunakan untuk mendukung serta melengkapi pemahaman peneliti mengenai isu terkait. Selanjutnya data tersebut akan dianalisis dengan menggunakan metode analisis deskriptif kualitatif.

\section{PEMBAHASAN}

Bentuk-Bentuk Mekanisme Penyelesaian Sengketa Yang Dapat Diterapkan Pada Perkara Malpraktik Medik Di Indonesia

Perkara malpraktik medik tidak muncul begitu saja, ada berbagai rentetan peristiwa yang mendahuluinya. Biasanya peristiwa pertama yang menjadi titik tolak munculnya sengketa antara pasien dengan pihak dokter dan/atau rumah sakit (sengketa medik) adalah munculnya akibat negatif dari suatu tindakan medik yang telah dilakukan. Bentuk penyelesaian sengketa yang timbul karena adanya dugaan malpraktik medik :

\section{Penyelesaian Sengketa Medik melalui Pengadilan}

Model penyelesaian sengketa melalui lembaga peradilan (in court settlement) dikenal pula dengan istilah penyelesaian secara litigasi (litigation). Mekanisme penyelesaian sengketa secara litigasi bersifat 'memutus' (adjudikasi)18. Penyelesaian sengketa terkait ${ }^{2}$ dugaan malpraktik medik secara litigasi (melalui mekanisme peradilan) dapat dilakukan baik melalui mekanisme peradilan perdata (civil court) maupun pidana (criminal court).Mekanisme peradilan sebenarnya lebih

\footnotetext{
2 Adjudikasi (adjudication) adalah mekanisme penyelesian sengketa yang bersifat memutus, dalam arti bahwa mekanisme ini menghasilkan putusan yang bersifat mengikat. Putusan tersebut diambil oleh pihak yang punya otoritas. Dalam hal penyelesaian sengketa dilakukan di lembaga pengadilan, maka pihak yang punya otoritas membuat putusan adalah hakim. Selain hakim, otoritas membuat putusan semacam itu juga dimiliki oleh seorang arbiter (wasit) melalui mekanisme arbitrase (arbitration). Dengan demikian, dapat difahami bahwa mekanisme penyelesaian sengketa melalui arbitrase ini bersifat adjudikasi (mirip dengan mekanisme peradilan), tetapi berjalan di luar jalur peradilan atau bersifat non litigasi.
} 
bernuansa

pertanggungjawaban

hukum(liability) daripada mekanisme penyelesaian sengketa (case settlement).

Gugatan terhadap dokter dan/atau rumah sakit terkait dugaan malpraktik medik didasarkan pada ketentuan pasal 1365 Kitab Undang-undang Hukum Perdata (BW). Pasal 1365 BW mengatur tentang perbuatan melawan hukum (onrechtmatige daad). Pasal tersebut menyatakan, tiap perbuatan melawan hukum yang mengakibatkan kerugian pada orang lain mewajibkan orang yang karena kesalahannya menerbitkan kerugian itu, mengganti kerugian. Dalam proses pemeriksaan di pengadilan (sidang) beban pembuktian ada pada penunutut umum. Penuntut umumlah yang harus membuktikan kesalahan terdakwa. Pembuktian materi dakwaan didasarkan pada alat-alat bukti yang telah dikumpulkan sebelumnya dan alat-alat bukti lain yang ditemukan kemudian. Jika hukum tidak mampu memberikan perlindungan kepada dokter, maka dokter akan menciptakan sistem perlindungan sendiri. Dalam dunia kedokteran, upaya untuk mengamankan dirinya dari resiko gugatan/tuntutan hukum dilakukan dengan menerapkan pola defensive medicine.

\section{Penyelesaian Sengketa Medik melalui MKDKI}

MKDKI adalah singkatan dari Majlis

Kehormatan Disiplin Kedokteran Indonesia.Secara kelembagaan MKDKI bernaung di bawah Konsil Kedokteran Indonesia (KKI), lembaga otonom yang bertanggungjawab langsung kepada presiden. Baik KKI maupun MKDKI dibentuk berdasarkan Undang-undang Nomor 29 Tahun 2004 Tentang Praktik Kedokteran (UU Praktik Kedokteran). Menurut ketentuan Pasal 55 ayat 1 UU Praktik Kedokteran, MKDKI dibentuk untuk menegakkan disiplin dokter dan dokter gigi dalam penyelenggaraan praktik kedokteran.Sedangkan menurut Pasal 64 poin (a) UU Praktik Kedokteran, MKDKI bertugasmenerima pengaduan, memeriksa, dan memutuskan kasus pelanggaran disiplin dokter dan dokter gigi.

Penyelesaian Perkara Malpraktik Medik melalui MKEK

MKEK singkatan dari Majlis

Kehormatan Etika Kedokteran. MKEK bernaung dibawah Ikatan Dokter Indonesia
(IDI) dan berfungsi untuk menegakkan etika kedokteran bagi para anggota organisasi profesi (IDI). Sesuai dengan berat ringannya pelanggaran, MKEK dapat menjatuhkan sanksi berupa teguran tertulis, skorsing sementara dari keanggotaan, pemecatan dari keanggotaan, serta pencabutan rekomendasi izin praktik selama-lamanya tiga tahun. Dengan berlakunya Undang-undang Praktik Kedokteran, mestinya MKEK melaksanakan pemeriksaan pelanggaran etika kedokteran setelah mendapat limpahan perkara dari MKDKI. Sebagaimana diatur dalam Pasal 68 Undang-undang Praktik Kedokteran, apabila dalam pemeriksaan ditemukan pelanggaran etika, MKDKI meneruskan pengaduan pada organisasai profesi.

Penyelesaian Perkara Malpraktik melalui mekanisme ADR

ADR adalah singkatan dari Alternative Dispute Resolution. Dalam bahasa Indonesia digunakan beberapa istilah seperti Penyelesaian Sengketa Alternatif, Alternatif Penyelesaian Sengketa dan lain-lain. ADR merujuk pada model penyelesaian sengketa di luar jalur pengadilan (non litigasi). Ada beberapa mekanisme penyelesaian sengketa yangmasuk kategori ADR yaitu arbitrase, negosiasi, mediasi dan konsiliasi. Terkait dengan sengketa medik, beberapa mekanisme ADR yang sering dipraktikkan untuk menyelesaikannya adalah arbitrase, negosiasi serta mediasi. Mekanisme mediasi mendapatkan penguatan dari Undang-undang Nomor 36 Tahun 2009 Tentang Kesehatan (UU Kesehatan). Berdasarkan ketentuan Pasal 29 UU Kesehatan,setiap sengketa yang timbul sebagai akibat adanya kelalaian tenaga kesehatan harus diselesaikan terlebih dahulu melalui mekanisme mediasi.

Penyelesaian Perkara Malpraktik Medik melalui BPSK

BPSK adalah singkatan dari Badan Penyelesaian Sengketa Konsumen. BPSK dibentuk berdasarkan perintah Undangundang Nomor 8 tahun 1999 tentang Perlindungan Konsumen (UU Perlindungan Konsumen). Secara kelembagaan BPSK bernaung di bawah Kementerian Perdagangan. Sesuai namanya, BPSK berfungsi untuk menyelesaikan sengketa konsumen, yaitu sengketa yang timbul antara pihak konsumen dan produsen. Sesuai ketentuan Pasal 52 huruf (a) UU 
Perlindungan Konsumen, BPSK menyelesaian sengketa menggunakan mekanisme mediasi, atau arbitrase atau konsiliasi.Meskipun domain dari BPSK adalah sengeta konsumen yang timbul di dunia perdagangan namun dalam praktik ada juga sengketa antara pasien dengan pihak rumah sakit yang dibawa ke BPSK. Secara teoritik, sebenarnya kewenangan BPSK untuk menyelesaikan sengketa medik masih diperdebatkan.

Hal ini didasarkan pada asumsi bahwa sengketa medik juga termasuk dalam kualifikasi sengketa konsumen sebagaimana dimaksud dalam UU Perlindungan Konsumen. Terdapat sejumlah fakta yang menguatkan asumsi tersebut, salah satunya adalah larangan dokter untuk mengiklankan diri (self promotion). Proses penyelesaian sengketa di BPSK dilakukan melalui tiga pilihan mekanisme, yaitu: arbitrase, konsiliasi, atau mediasi. Jika BPSK beranggapan bahwa konsumen (pasien) telah dirugikan oleh tindakan produsen (dokter/rumah sakit), BPSK dapat menjatuhkan sanksi administratif berupa ganti kerugian paling banyak 200 juta rupiah kepada produsen (dokter/rumah sakit).

\section{Mediasi: Mekanisme Ideal Untuk Menyelesaikan Sengketa Medik}

Dari berbagai kajian yang telah dilakukan, peneliti menemukan bahwa mediasi merupakan mekanisme paling ideal untuk penyelesaian sengketa medik di Indonesia. Kesimpulan itu didasarkan pada berbagai pertimbangan yaitu:

a) Mekanisme mediasi bertumpu pada pola musyawarah untuk mufakat yang sesuai dengan budaya bangsa Indonesia;

b) Sebagai salah satu cara menyelesaikan sengketa di luar pengadilan, mekanisme mediasi terbebas dari berbagai kelemahan instrinsik yang ada pada mekanisme litigasi seperti prosedurnya kompleks, waktunya lama, dan biayanya mahal;

c) Mekanisme mediasi menawarkan penyelesaian yang bersifat win-win solution;

d) Mekanisme mediasi memberi ruang dialog yang cukup antara pihak yang besengketa; dan

e) Mekanisme mediasi memiki katup pengaman (dalam hal ini mediator) yang mampu mencairkan kebekuan komunikasi antara dua pihak yang bersengketa.

\section{Mediasi dalam Berbagai Peraturan Perundang-undangan}

Tidak berlebihan jika dikatakan bahwa mediasi merupakan mekanisme penyelesaian sengketa di luar pengadilan yang paling populer di Indonesia, jika di bandingkan dengan mekanisme penyelesaian sengketa non litigasi lainnya. Prosedur mediasi dipraktikkan di berbagai lembaga seperti pengadilan, ombudsman, BPSK, BPRS, dan sudah barang tentu di berbagai lembaga swadaya masyarakat yang memang secara khusus didirikan untuk memberikan pelayanan mediasi seperti Pusat Mediasi Nasional (PMN), Badan Mediasi Indonesia (BAMI) dan Indonesian Institute for Conflict Transformation (IICT). Ketentuan tentang mediasi juga terdapat di dalam berbagai peraturan perundang-undangan yaitu Undang-undang Nomor 8 Tahun 1999 Tentang Perlindungan Konsumen, Undangundang Nomor 30 Tahun 1999 Tentang Arbitrase dan Alternatif Penyelesaian Sengketa, Peraturan Mahkamah Agung Nomor 1 Tahun 2008 Tentang Prosedur Mediasi di Pengadilan, dan Undang-undang Nomor 36 Tahun 2009 Tentang Kesehatan.

Dengan begitu maka ancaman kriminalisasi terhadap dokter benar-benar memperoleh legitimasi. Secara normatif tidak keliru pembuat undang-undang (legislator) membuat rumusan-rumusan delik semacam itu. Masalah akan timbul di tingkat penerapan dan penegakannya. Tidak mudah memastikan terpenuhinya unsur-unsur delik sebagaimana diatur dalam Pasal 84 UU Kesehatan tersebut. Membuktikan telah terjadinya luka berat atau pun kematian pada pihak pasien memang tidak sulit, yang sulit adalah membuktikan unsur kelalaian dokter serta unsur hubungan sebab akibat (causal link) antara kelalaian dokter dengan luka berat atau kematian yang dialami oleh pasien. Unsur kelalaian tidak dapat dinilai oleh hakim dan ditentukan semata-mata berdasarkan penilaian juridis.

\section{KESIMPULAN}

Berdasarkan hasil penelitian dan pembahasan di atas, dapat disimpulkan beberapa hal sebagai berikut:

a) Berdasarkan ketentuan-ketentuan yang terdapat di dalam berbagai peraturan perundang-undangan yang ada, perkara 
malpraktik medik dapat diselesaikan baik secara litigasi maupun non litigasi. Penyelesaian secara litigasi dapat dilakukan melalui peradilan perdata maupun pidana. Penyelesaian secara non litigasi dapat dilakukan melalui berbagai lembaga seperti MKDKI, MKEK, ADR, Ombudsman dan BPSK.

b) Mediasi adalah cara paling ideal untuk menyelesaian perkara malpraktik medik. Mekanisme ini telah dilembagakan secara khusus melalui Undang-undang Nomor 36 Tahun 2009 Tentang Kesehatan (UU Kesehatan) dan dikuatkan oleh Undangundang Nomor 36 tahun 2014 Tentang Tenaga Kesehatan (UU Tenaga Kesehatan). Meskipun telah diatur sejak tahun 2009, pelaksanaan mediasi belum menggembirakan karena terkendala oleh berbagai macam faktor seperti tidak adanya peraturan pelaksana ketentuan mediasi dan mindset anggota masyarakat serta aparat yang cenderung menganggab peristiwa yang secara sosiologis disebut malpraktik medik, khususnya yang mengakibatkan luka-luka dan kematian, sebagai peristiwa pidana.

\section{E. DAFTAR PUSTAKA}

Adami Chazawi, Malpraktike Kedokteran: Tinjauan Norma dan Doktrin Hukum, Malang:Bayu Media, 2007.

Danny Wiradharma, Inge Rusli, dan Dionisia Sri Hartati, Alternatif Penyelesaian SengketaMedik, Jakarta: Sagung Seto, 2011.

Eddi Junaidi, Mediasi dalam Penyelesaian Sengketa Medik, Jakarta: Rajawali Press, 2011.

Mudakir Iskandarsyah, Tuntutan Pidana dan Perdata Malpraktik, Jakarta: Permata Aksara, 2011.

Rinanto Suryadhimirtha, Hukum Malapraktik Kedokteran, Yogyakarta: Total Media, 2011.

S. Soetrisno, Malpraktek Medik dan Mediasi sebagai Alternatif Penyelesaian Sengketa,Jakarta: Telaga Ilmu, 2010.

Jakarta: Penerbit Buku Kedokteran EGC, 2009.
Safitri Hariyani, Sengketa Medik: Alternatif Penyelesaian Perselisiban antara Dokterdengan Pasien, Jakarta: Diadit Media, 2005.

Puteri Nemie, Medical Negligence, Kuala Lumpur: International Law Book Service, 2003.

Sal Fiscina, et al, Medical Liability, St. Paul: West Publishing Co, 1991.

Widodo Trisno Novianto, Alternatif Model Penyelesaian Sengketa Medik di Luar Pengadilan melalui Lembaga Penyelesaian Sengketa Medik dalam Pelayanan Kesehatan,Surakarta: UNS Press, 2014. 